\title{
Interação entre fungos micorrízicos arbusculares e bactérias diazotróficas em trigo
}

\author{
Valéria Marino Rodrigues Sala ${ }^{(1)}$, Sueli dos Santos Freitas ${ }^{(1)}$ e Adriana Parada Dias da Silveira ${ }^{(1)}$
}

\author{
(1)Instituto Agronômico, Centro de Solos e Recursos Ambientais, Caixa Postal 28, CEP 13001-970 Campinas, SP. E-mail: valeriamarino@uol.com.br, \\ sfreitas@iac.sp.gov.br, apdsil@iac.sp.gov.br
}

\begin{abstract}
Resumo - O objetivo deste trabalho foi avaliar o efeito da inoculação de dois novos isolados de bactérias diazotróficas endofíticas e da interação destas bactérias com fungos micorrízicos arbusculares (FMAs), na cultura do trigo. Foi realizado um experimento em casa de vegetação, com dois isolados de bactérias diazotróficas endofíticas, IAC11HT (Achromobacter insolitus) e IAC12HT (Zoogloea ramigera), e dois FMAs (Glomus sp. e Acaulospora sp.). Houve efeito sinérgico da co-inoculação na colonização das raízes por bactérias diazotróficas, com o emprego do FMA do gênero Acaulospora. As plantas associadas a Glomus, na presença dos isolados bacterianos, apresentaram maior crescimento, acúmulo e aproveitamento dos nutrientes do que as plantas colonizadas por Acaulospora sp., entretanto, não superaram os tratamentos em que as bactérias e os fungos foram inoculados isoladamente. Apesar de não ter havido efeito benéfico da co-inoculação FMA-bactéria diazotrófica sobre a maioria dos parâmetros avaliados, essas novas bactérias propiciaram o dobro de crescimento, acúmulo e aproveitamento do $\mathrm{N}$ e $\mathrm{P}$ em plantas de trigo.
\end{abstract}

Termos para indexação: Zoogloea ramigera, Achromobacter insolitus, micorriza arbuscular, nitrogênio, fósforo.

\section{Interaction between arbuscular mycorrhizal fungi and diazotrophic bacteria in wheat plants}

\begin{abstract}
The aim of this work was to evaluate the inoculation effect of two new endophytic diazotrophic bacteria and the interaction between arbuscular mycorrhizal fungi (AMF) and these bacteria on wheat plants. The experiment was carried out in a greenhouse with the two strains of diazotrophic bacteria, IAC11HT (Achromobacter insolitus) and IAC12HT (Zoogloea ramigera), and two AMF (Glomus sp. and Acaulospora sp.). There was synergistic effect of the co-inoculation on root colonization by diazotrophic bacteria with the AMF of the genus Acaulospora. The plants colonized by Glomus associated to bacterial strains showed higher growth, accumulation and exploitation of the nutrients than plants colonized by Acaulospora sp., however, this effect did not surpass the treatments in which bacteria and fungi were inoculated separately. Although there were nonbeneficial effects of the AMF-diazotrophic bacteria co-inoculation, for the most parameters assessed, these news bacteria strains promoted doubled shoot dry matter, shoot $\mathrm{N}$ and $\mathrm{P}$ concentration and accumulation in wheat plants.
\end{abstract}

Index terms: Zoogloea ramigera, Achromobacter insolitus, arbuscular mycorrhiza, nitrogen, phosphorus.

\section{Introdução}

No solo há grande diversidade de microrganismos que estão em constante interação, principalmente na rizosfera das plantas, em razão da grande quantidade de nutrientes secretados e liberados pelas raízes, como lisados e exsudatos radiculares. Entretanto, essas interações são pouco estudadas, como as que ocorrem na micorrizosfera, entre os fungos micorrízicos arbusculares (FMAs) e as bactérias diazotróficas. Esses dois grupos de microrganismos estão associados à maioria das plantas cultivadas e são reconhecidamente benéficos, pelo incremento na absorção de nutrientes escassos no ambiente e, conseqüentemente, na promoção de crescimento das plantas (Artursson et al., 2006).

As bactérias diazotróficas podem auxiliar, por meio de diversos mecanismos, na nutrição nitrogenada das culturas, como o aumento do processo da redução assimilatória de nitrato disponível no solo (Boddey et al., 1986), pela fixação biológica do $\mathrm{N}_{2}(\mathrm{FBN})$ (Iniguez et al., 2004) e pela produção de fitormônios que interferem no crescimento das plantas e podem alterar a morfologia 
das raízes, o que possibilita a exploração de maior volume de solo (Zaied et al., 2003).

A transmissão de bactérias diazotróficas para plantas pode estar relacionada à presença de FMA, como demonstrado por Paula et al. (1991) e Li \& Strzelczyk (2000). A bactéria está presente em esporos de fungos micorrízicos, mas ainda se desconhece sua função. No processo de penetração das hifas infectivas, pode ocorrer maior exsudação de nutrientes pela planta, o que acelera o crescimento de tais bactérias (Paula et al., 1991). Em contrapartida, as bactérias diazotróficas associadas a esporos de FMAs podem promover o aumento e rápida colonização pelo fungo, o que pode favorecer o desenvolvimento de um inoculante comercial de FMAs (Bhowmik \& Singh, 2004).

Existem vários relatos dos efeitos benéficos propiciados pela interação FMA-bactéria diazotrófica (Clark et al., 1999; Bhowmik \& Singh, 2004; Barea et al., 2005), principalmente com os FMAs dos gêneros Glomus e Acaulospora, que são os mais eficientes e abundantes nos solos agrícolas (Graham \& Abbott, 2000). Segundo Artursson et al. (2006), os benefícios da interação FMA-bactéria diazotrófica podem ocorrer em razão do incremento na absorção de $\mathrm{P}$ pelas plantas micorrizadas, o que propicia melhores condições para o estabelecimento da associação com diazotróficos, o que representa, por sua vez, alto custo energético. Essas interações podem ser de extrema importância para uma agricultura com menor emprego de insumos químicos, como os fertilizantes nitrogenados e fosfatados.

O objetivo deste trabalho foi avaliar o efeito da inoculação de dois novos isolados de bactérias diazotróficas, dos gêneros Achromobacter e Zoogloea, descobertos recentemente, associados a plantas de trigo, e o efeito da interação dessas bactérias com FMAs na cultura do trigo.

\section{Material e Métodos}

O experimento foi realizado em casa de vegetação, com delineamento inteiramente ao acaso e cinco repetições, tendo-se empregado dois isolados bacterianos, IAC11HT (Achromobacter insolitus) e IAC12HT (Zooglea ramigera), e dois isolados de FMA, pertencentes aos gêneros Acaulospora sp. (IAC-13) e Glomus sp. (IAC-22), e o genótipo de trigo ITD-19 (Triticum durum L.). Os isolados bacterianos utilizados, IAC11HT (acesso no Genbank no DQ386150) e IAC12HT (acesso no Genbank no DQ389143), foram obtidos de raízes de plantas de trigo do genótipo ITD19, desinfestadas superficialmente, e que promoveram aumento no crescimento das raízes em condições gnotobióticas (Sala et al., 2005).

As sementes foram desinfestadas segundo Döbereiner et al. (1995) e pré-germinadas em placas de Petri, com meio de cultura BDA, para se verificar a ausência de contaminantes, e só então foram transferidas para tubos de ensaio de $200 \mathrm{~mL}$, com solução de Hoagland \& Arnon (1950) sem N, e 0,6\% de ágar. As bactérias foram inoculadas, tendo-se utilizado $1 \mathrm{~mL}$ de inóculo por tubo, antes da solidificação do ágar, após terem atingido a fase log de crescimento em meio JNFb, que foi utilizado para repicagem dos isolados (Döbereiner et al., 1995). As plantas-testemunha receberam $1 \mathrm{~mL}$ de inóculo esterilizado por autoclavagem. Depois de sete dias, as plantas foram transplantadas para vasos com capacidade de 2,5 L, com areia esterilizada como substrato, em casa de vegetação.

Nos tratamentos com FMA empregou-se solo-inóculo, com aproximadamente 6.000 esporos do fungo micorrízico por vaso, pedaços de raiz de braquiária colonizada e hifas. Nos vasos sem inoculação de FMA, adicionou-se uma suspensão de solo isenta de propágulos de FMAs. Foram realizados 11 tratamentos: $Z$. ramigera (IAC12HT), A. insolitus (IAC11HT), Glomus sp., Acaulospora sp., Z. ramigera + Glomus sp., Z. ramigera + Acaulospora sp., A. insolitus + Glomus sp., A. insolitus + Acaulospora sp., testemunha sem $\mathrm{N}$ (controle sem adição de $\mathrm{N}$ ), testemunha sem $\mathrm{P}$ (controle com adição de $\mathrm{N}$ e metade da quantidade de $\mathrm{P}$ da solução completa) e testemunha + N (controle com solução completa).

As plantas receberam solução nutritiva (Furlani \& Furlani, 1988), duas vezes por semana, e água esterilizada quando necessário. Os tratamentos com bactérias e o controle sem $\mathrm{N}$ (testemunha-N) receberam solução nutritiva sem $\mathrm{N}$ e com metade da quantidade de $\mathrm{P}$ da solução completa. Os tratamentos somente com FMA e testemunha-P receberam solução nutritiva com $\mathrm{N}$ e metade da quantidade de $\mathrm{P}$ da solução completa, e o controle recebeu solução nutritiva completa.

As plantas permaneceram dois meses em casa de vegetação e, depois deste período, foram colhidas, e a parte aérea foi separada do sistema radicular. Após determinação da massa da matéria seca (secada em estufa a $60^{\circ} \mathrm{C}$ até massa constante), a parte aérea foi moída para determinação dos teores de $\mathrm{N}$ e $\mathrm{P}$, e foram 
calculados a quantidade acumulada (gramas de $\mathrm{N}$ por vaso) e o índice de eficiência de utilização [(massa da matéria seca da parte aérea) ${ }^{2}$ /quantidade acumulada do nutriente], segundo Siddiqi \& Glass (1981). As raízes foram separadas, para a avaliação da massa da matéria fresca e da colonização micorrízica (Phillips \& Hayman, 1970) e, para a contagem de bactérias diazotróficas endofíticas, foi utilizado o meio JNFb semi-sólido e sem adição de N (Döbereiner et al., 1995)

Os dados obtidos foram analisados pelo programa Minitab, tendo-se feito a análise da variância. As médias dos tratamentos foram comparadas por contrastes ortogonais, testados pelo teste $\mathrm{F}$, a $5 \%$ de probabilidade.

\section{Resultados e Discussão}

A inoculação do FMA do gênero Acaulospora aumentou a colonização por bactérias diazotróficas, nas raízes do trigo em que bactéria e fungo micorrízico foram co-inoculados (BF1 - BF2), para ambas as bactérias coinoculadas, e nos tratamentos em que os FMAs foram inoculados separadamente (F1 - F2) (Tabela 1). Vários autores já demonstraram a ocorrência de bactérias diazotróficas endofíticas, na superfície e dentro de esporos de FMAs (Paula et al., 1991; Li \& Strzelczyk, 2000; Bianciotto et al., 2004). Li \& Strzelczyk (2000) sugerem que as bactérias diazotróficas podem contribuir para a nutrição dos FMAs, ao tornar disponível o nitrogênio. Os mesmos autores isolaram Azospirillum spp. da superfície de diferentes espécies de FMAs. A ocorrência de bactérias diazotróficas endofíticas, dentro ou na superfície de esporos de FMAs, parece estar relacionada

Tabela 1. Número de bactérias diazotróficas endofíticas (BDE) na raiz de trigo e teste $\mathrm{F}$ para comparação dos contrastes ortogonais obtidos entre os tratamentos. Média de cinco repetições ${ }^{(1)}$.

\begin{tabular}{lccc}
\hline Tratamento $^{(2)}$ & $\begin{array}{c}\mathrm{BDE} \\
\left(\mathrm{n}^{\mathbf{0}} \mathrm{Mg}^{-1}\right)\end{array}$ & $\begin{array}{c}\text { Contrastes } \\
\text { ortogonais }\end{array}$ & Teste F \\
\hline B1 & 0,330 & $\mathrm{BF}-\mathrm{B}$ & $4,29^{*}$ \\
$\mathrm{~B} 1 \mathrm{~F} 1$ & 0,061 & $\mathrm{BF} 1-\mathrm{BF} 2$ & $55,43^{*}$ \\
$\mathrm{~B} 1 \mathrm{~F} 2$ & 0,370 & $\mathrm{~B} 1 \mathrm{~F}-\mathrm{B} 2 \mathrm{~F}$ & $2,50^{\mathrm{ns}}$ \\
$\mathrm{B} 2$ & 0,116 & $\mathrm{BF}-\mathrm{F}$ & $17,35^{*}$ \\
$\mathrm{~B} 2 \mathrm{~F} 1$ & 0,044 & $\mathrm{~F} 1-\mathrm{F} 2$ & $5,25^{*}$ \\
$\mathrm{~B} 2 \mathrm{~F} 2$ & 0,419 & $\mathrm{~B} 1-\mathrm{B} 2$ & $6,29^{*}$ \\
F1 & 0,026 & - & - \\
F2 & 0,065 & - & - \\
\hline
\end{tabular}

(1) Para análise estatística os dados foram transformados em $\log (\mathrm{x}+1)$; $\mathrm{GL}=1 \mathrm{e} 32 ; \mathrm{F}_{0}=4,15$. (2) $\mathrm{B} 1:$ IAC12HT - Zoogloea ramigera; B2: IAC11HT - Achromobacter insolitus; F1: Glomus sp.;

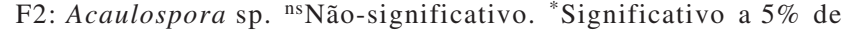
probabilidade pelo teste $\mathrm{F}$. à espécie do fungo, à planta hospedeira e, ainda, ao substrato utilizado (Artursson et al., 2006). Como foi empregado solo-inóculo para inoculação do FMA, não é possível afirmar-se que, neste caso, somente o FMA tenha sido um agente transmissor de bactérias diazotróficas. Behl et al. (2003) obtiveram efeito contrário ao deste trabalho com a co-inoculação do FMA do gênero Glomus, pois houve aumento da colonização por bactérias diazotróficas em plantas de trigo. Porém, Isopi et al. (1995) observaram, em plantas de sorgo colonizadas por G. diazotrophicus e três espécies de Glomus, que a quantidade de bactérias não aumentou com a coinoculação de FMAs.

Quando as diazotróficas foram inoculadas isoladamente, houve maior colonização nas raízes do trigo com a inoculação de $Z$. ramigera do que com A. insolitus (B1 - B2). Entretanto, na presença do FMA, não houve diferença na colonização radicular, entre os isolados bacterianos utilizados (B1F - B2F).

A co-inoculação das bactérias também influenciou a colonização micorrízica; $A$. insolitus promoveu maior colonização micorrízica do que $Z$. ramigera $(\mathrm{B} 1 \mathrm{~F}$ - B2F) (Tabela 2). No entanto, os FMAs não diferiram entre si quanto à colonização radicular, nos tratamentos que receberam somente FMA (F1 - F2), e também, quando co-inoculados com as bactérias (BF1 - BF2).

Biró et al. (2000) utilizaram, em plantas de alfafa, G. fasciculatum em combinação com A. brasilense ou Rizobium meliloti, ou os três inóculos conjuntamente, e observaram que a colonização micorrízica variou entre as bactérias utilizadas na associação, o que demonstra especificidade da interação fungo-planta-bactéria. Vázquez et al. (2000) observaram que a inoculação de Azospirillum não influenciou a colonização por Glomus

Tabela 2. Colonização micorrízica nas raízes de trigo e teste F para comparação dos contrastes ortogonais obtidos entre os tratamentos. Média de cinco repetições ${ }^{(1)}$.

\begin{tabular}{lccc}
\hline Tratamento $^{(2)}$ & $\begin{array}{c}\text { Porcentagem } \\
\text { de colonização }\end{array}$ & $\begin{array}{c}\text { Contrastes } \\
\text { ortogonais }\end{array}$ & Teste F \\
\hline B1F1 & 26,80 & BF1 - BF2 & $1,55^{\text {ns }}$ \\
B1F2 & 29,20 & B1F - B2F & $30,62^{*}$ \\
B2F1 & 33,25 & BF - F & $103,22^{*}$ \\
B2F2 & 33,00 & F1 - F2 & $1,79^{\text {ns }}$ \\
F1 & 39,80 & - & - \\
F2 & 38,00 & - & - \\
\hline
\end{tabular}

(1) Para análise estatística os dados foram transformados em $\operatorname{arc} \operatorname{sen}(\mathrm{x} / 100)^{0,5} ; \mathrm{GL}=1$ e $23 ; \mathrm{F}_{0}=4,28 .{ }^{(2)} \mathrm{B} 1: \mathrm{IAC} 12 \mathrm{HT}-$ Zoogloea ramigera; B2: IAC11HT - Achromobacter insolitus; F1: Glomus sp.;

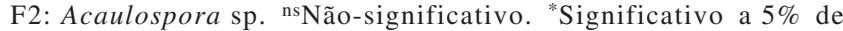
probabilidade pelo teste $\mathrm{F}$. 
deserticola e G. mosseae, em plantas de milho. Entretanto, Bhowmik \& Singh (2004) sugerem que bactérias associadas a esporos de FMAs podem promover aumento e rápida colonização pelo fungo, o que representa uma importante informação para o desenvolvimento de um inoculante comercial de FMAs.

Neste trabalho, a colonização micorrízica foi maior quando somente os FMAs foram inoculados, em comparação com os tratamentos com ambos os endófitos. Pode ter havido competição entre FMAs e bactérias na colonização das raízes, pois, como observado por Biró et al. (2000), em raízes de cereais colonizadas por Azospirillum spp. e FMAs, ambos os endófitos podem estar presentes na mesma área cortical das raízes e tornar possível uma interação direta entre planta-bactéria-FMA, o que pode resultar em competição por compostos fotossintetizados. O efeito constatado também pode ser atribuído à diferença na solução nutritiva, pois os tratamentos em que bactéria e fungo foram co-inoculados não receberam $\mathrm{N}$, e os tratamentos só com FMA receberam $\mathrm{N}$, porém ambos tiveram a mesma quantidade de $\mathrm{P}$ adicionada. A planta mais bem nutrida teve melhor condição para a colonização por FMAs, pois suportou o alto custo energético envolvido na simbiose, uma vez que os mecanismos de regulação da colonização são funcionalmente dependentes do carbono disponível para o fungo (Barea et al., 2005).

As plantas colonizadas por Glomus e pelos isolados bacterianos apresentaram maior massa de matéria seca da parte aérea do que as colonizadas por Acaulospora (BF1 - BF2). Vázquez et al. (2000) observaram efeito da co-inoculação de Azospirillum sp. com duas espécies de FMAs sobre a produção de massa de matéria seca de milho, e também obtiveram efeito positivo apenas com uma espécie de FMA, a G. deserticola. Neste trabalho, porém, não houve diferença entre os tratamentos que receberam somente FMAs (F1 - F2) (Tabela 3). A produção de matéria seca da parte aérea foi maior nos tratamentos em que os FMAs foram inoculados isoladamente, em comparação com os tratamentos com ambos os endófitos (BF - F), o que demonstra que não houve efeito sinérgico. Também, não ocorreu sinergismo nos tratamentos com inoculação das bactérias isoladamente (BF - B), ao contrário, houve interação negativa, parasítica, entre o FMA do gênero Acaulospora e as bactérias diazotróficas, o que acarretou diminuição significativa da produção de matéria seca, e não diferiu somente da testemunha sem nitrogênio (BF - T - N).
Em plantas com alta dependência micorrízica como a batata doce, os efeitos sinérgicos são mais pronunciados. Os benefícios da co-inoculação ocorrem graças ao aumento na colonização micorrízica, e conseqüentemente, da maior assimilação de nutrientes do solo, e não em razão da fixação biológica de $\mathrm{N}_{2}$ (Paula et al., 1992). $\mathrm{O}$ trigo, por seu sistema radicular fasciculado, apresenta pouca dependência micorrízica.

As bactérias inoculadas isoladamente duplicaram o crescimento das plantas, em relação à testemunha que recebeu a mesma solução nutritiva $(B-T-N)$, sem adição de N. Nos tratamentos com FMAs somente, a matéria seca foi menor do que na testemunha que recebeu a mesma solução nutritiva $(\mathrm{F}-\mathrm{T}-\mathrm{P})$. Possivelmente, a quantidade de P utilizada na solução nutritiva foi alta, uma vez que o substrato utilizado foi areia e que todo $P$ estava disponível na solução do solo. Graham \& Abbott (2000) avaliaram o efeito de 10 diferentes isolados de FMAs em trigo e constataram que apenas dois isolados foram capazes de proporcionar maior massa de matéria seca do que a testemunha, e somente em baixo nível de P. Esses autores sugerem que tal efeito esteja relacionado à alta colonização por esses fungos, que denominaram de agressivos. Clark et al. (1999) observaram que não houve correlação entre a porcentagem de colonização e massa da matéria seca da parte aérea ou da raiz, em plantas de trigo.

Tabela 3. Massa da matéria seca da parte aérea (MSPA) de trigo e teste $\mathrm{F}$ para comparação dos contrastes ortogonais obtidos entre os tratamentos. Média de cinco repetições ${ }^{(1)}$.

\begin{tabular}{lccr}
\hline Tratamento $^{(2)}$ & $\begin{array}{c}\text { MSPA } \\
\text { (g por planta) }\end{array}$ & $\begin{array}{c}\text { Contrastes } \\
\text { ortogonais }\end{array}$ & Teste F \\
\hline B1 & 3,08 & BF - F & $339,43^{*}$ \\
B1F1 & 3,12 & BF - B & $15,43^{*}$ \\
B1F2 & 1,32 & BF1 - BF2 & $40,41^{*}$ \\
B2 & 3,30 & B1F - B2F & $0,37^{\text {ns }}$ \\
B2F1 & 3,12 & F - T - P & $11,32^{*}$ \\
B2F2 & 0,94 & B - T - N & $19,35^{*}$ \\
F1 & 6,94 & BF - T - N & $3,18^{\text {ns }}$ \\
F2 & 7,32 & B - F & $322,12^{*}$ \\
T + N & 6,44 & F1 - F2 & $0,73^{\text {ns }}$ \\
T - N & 1,50 & B1 - B2 & $0,25^{\text {ns }}$ \\
T - P & 8,42 & BF1 - B & $0,01^{\text {ns }}$ \\
& & BF2 - B & $43,13^{*}$ \\
& & T - P - T + N & $20,00^{*}$ \\
\hline
\end{tabular}

${ }^{(1)} \mathrm{GL}=1$ e $42 ; \mathrm{F}_{0}=4,05 .{ }^{(2)} \mathrm{B} 1:$ IAC $12 \mathrm{HT}-$ Zoogloea ramigera; B2: IAC11HT - Achromobacter insolitus; F1: Glomus sp.; F2: Acaulospora sp.; T + N: testemunha que recebeu solução nutritiva completa; $\mathrm{T}$ - N: testemunha que recebeu metade da quantidade de $\mathrm{P}$ da solução completa e não recebeu $\mathrm{N}$; T - P: testemunha que recebeu metade

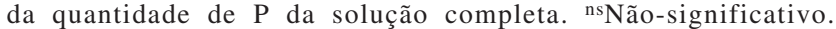
${ }^{*}$ Significativo a $5 \%$ de probabilidade pelo teste F. 
A bactéria diazotrófica utilizada influenciou a massa da matéria fresca das raízes, nos tratamentos em que a bactéria e o fungo micorrízico foram co-inoculados (Tabela 4). Com o emprego de Z. ramigera, obteve-se maior massa de raízes do que com a inoculação de A. insolitus (B1F-B2F), entretanto, não houve diferenças entre os tratamentos com bactérias diazotróficas isoladamente (B1 - B2). Houve influência do FMA sobre a massa da matéria fresca das raízes, com a co-inoculação (BF1 - BF2), tendo havido maior crescimento radicular com Glomus do que com Acaulospora, mas somente na presença de $Z$. ramigera (B1F1 - B1F2). Também não houve diferenças entre os tratamentos que continham somente FMAs (F1 - F2). Novamente, o nível de $\mathrm{N}$ na solução nutritiva parece ter influenciado o comportamento dos microrganismos, pois houve diferenças entre os tratamentos na ausência de $\mathrm{N}$, porém, quando se adicionou $\mathrm{N}$ não se observou influência dos FMAs utilizados. Os FMAs isoladamente não influenciaram a massa da matéria fresca das raízes, em comparação com a testemunha que recebeu a mesma solução nutritiva (F - T - P). Este fato pode estar relacionado à influência da solução nutritiva sobre o efeito do FMA. Porém, nos tratamentos que continham somente bactérias diazotróficas, obteve-se o dobro da massa de matéria fresca da raiz do que na testemunha (B - T - N). Já foi observado que esses isolados

Tabela 4. Massa da matéria fresca da raiz (MFR) de plantas de trigo e teste $\mathrm{F}$ para comparação dos contrastes ortogonais obtidos entre os tratamentos. Média de cinco repetições ${ }^{(1)}$.

\begin{tabular}{lccr}
\hline Tratamento $^{(1)}$ & $\begin{array}{c}\text { MFR } \\
\left(\mathrm{g} \text { planta }^{-1}\right)\end{array}$ & $\begin{array}{c}\text { Contrastes } \\
\text { ortogonais }\end{array}$ & Teste F \\
\hline B1 & 6,82 & BF - F & $223,36^{*}$ \\
B1F1 & 5,16 & BF - B & $217,45^{*}$ \\
B1F2 & 2,44 & BF1 - BF2 & $18,80^{*}$ \\
B2 & 6,87 & B1F - B2F & $37,46^{*}$ \\
B2F1 & 1,88 & F - T - P & $2,12^{\text {ns }}$ \\
B2F2 & 1,88 & B - T - N & $85,00^{*}$ \\
F1 & 6,74 & BF - T - N & $1,75^{\text {ns }}$ \\
F2 & 7,06 & B - F & $0,03^{\text {ns }}$ \\
T + N & 10,88 & F1 - F2 & $0,52^{\text {ns }}$ \\
T - N & 3,30 & B1 - B2 & $0,01^{\text {ns }}$ \\
T - P & 7,46 & B1F1 - BIF2 & $37,59^{*}$ \\
& & B1F1 - BF & $72,93^{*}$ \\
& & B2FI - B2F2 & $0,01^{\text {ns }}$ \\
\hline
\end{tabular}

${ }^{(1)} \mathrm{GL}=1$ e $41 ; \mathrm{F}_{0}=4,08 .{ }^{(2)} \mathrm{B} 1:$ IAC12HT - Zoogloea ramigera; B2: IAC11HT - Achromobacter insolitus; F1: Glomus sp.; F2: Acaulospora sp.; T + N: testemunha que recebeu solução nutritiva completa; $\mathrm{T}$ - N: testemunha que recebeu metade da quantidade de $\mathrm{P}$ da solução completa e não recebeu $\mathrm{N}$; $\mathrm{T}$ - P: testemunha que recebeu metade da quantidade de $\mathrm{P}$ da solução completa. ns'Não-significativo. ${ }^{*}$ Significativo a $5 \%$ de probabilidade pelo teste $\mathrm{F}$. promoveram aumento no crescimento das raízes, em condições gnotobióticas (Sala et al., 2005). Vários efeitos na morfologia das raízes colonizadas por bactérias diazotróficas endofíticas, como aumento no comprimento, no número de ramificações, da superfície e, ainda, de pêlos radiculares, já foram relatados (Dobbelaere et al., 1999; Roesch et al., 2005). Estes efeitos, geralmente, estão relacionados à produção de hormônios de crescimento pela bactéria, e já foi demonstrado que isolados pertencentes aos gêneros Achromobacter e Zoogloea podem sintetizar ácido indolacético (AIA), em cultura pura de células (Tsavkelova et al., 2006).

No tratamento em que as bactérias e os FMAs foram co-inoculados na planta, a massa de raiz não foi alterada, comparativamente à testemunha que recebeu a mesma solução nutritiva (BF - T - N). Porém, a testemunha que recebeu solução nutritiva completa $(\mathrm{T}+\mathrm{N})$ superou todos os demais tratamentos no crescimento radicular (Tabela 4).

Azcón \& Ocampo (1981) observaram que as diferenças na dependência micorrízica, entre cultivares de trigo, foi relacionada inversamente ao comprimento radicular e não à concentração de $\mathrm{P}$ nos tecidos dessas plantas, o que também poderia explicar a falta de efeito sinérgico FMA-bactéria diazotrófica, ao ser avaliada a colonização micorrízica (Tabela 2), uma vez que as bactérias proporcionaram aumento do crescimento radicular.

As plantas dos tratamentos, em que somente os FMAs foram inoculados, apresentaram maior teor, quantidade acumulada e índice de eficiência de utilização do $\mathrm{N}$, em comparação aos tratamentos com ambos os endófitos (BF - F) (Tabela 5). Houve efeito sinérgico da co-inoculação no teor de $\mathrm{N}$ das plantas, em comparação aos tratamentos com as bactérias isoladamente, os quais receberam a mesma solução nutritiva (B - BF), e o FMA do gênero Acaulospora, associado à $Z$. ramigera $(\mathrm{B} 1-\mathrm{B} 1 \mathrm{~F} 2)$, promoveu o aumento do teor de $\mathrm{N}$ das plantas. Entretanto, o FMA do gênero Glomus propiciou maior quantidade acumulada e maior índice de eficiência de utilização (IEU) do N, independentemente da bactéria empregada (BF1 - BF2), nos tratamentos com ambos os endófitos, em razão da maior massa de matéria seca da parte aérea produzida (Tabela 3). Porém, os tratamentos com FMAs isoladamente não diferiram entre si (F1 - F2).

Não houve diferenças entre as bactérias diazotróficas utilizadas, ao serem avaliados a absorção e o 
aproveitamento do $\mathrm{N}$ na parte aérea com a co-inoculação dos FMAs (B1F - B2F) (Tabela 5). Porém, nos tratamentos em que as bactérias foram inoculadas isoladamente (B1 - B2), houve aumento no teor de N das plantas com a inoculação de A. insolitus. Nos tratamentos que continham somente bactérias diazotróficas, obteve-se o menor teor, porém o dobro da quantidade acumulada e do índice de eficiência de utilização do $\mathrm{N}$ do que na testemunha que recebeu a mesma solução nutritiva (B - T - N).

As bactérias inoculadas isoladamente propiciaram o mesmo IEU de $\mathrm{N}$ que as plantas testemunha que receberam solução nutritiva completa $(\mathrm{B}-\mathrm{T}+\mathrm{N})$, porém, nos tratamentos em que a bactéria foi coinoculada com os FMAs, as plantas apresentaram IEU de $\mathrm{N}$ inferior ao da testemunha $(\mathrm{BF}-\mathrm{T}+\mathrm{N})$, o que mostra que a co-inoculação com FMAs teve efeito negativo no aproveitamento do $\mathrm{N}$ pelas plantas.

Nos tratamentos com FMAs isoladamente, não houve diferenças no IEU de $\mathrm{N}$, em relação à testemunha com a mesma solução nutritiva (F - T - P). Entretanto, essas plantas apresentaram maior IEU do $\mathrm{N}$ do que as plantas da testemunha que receberam solução nutritiva completa $(\mathrm{F}-\mathrm{T}+\mathrm{N})$. As duas testemunhas receberam a mesma quantidade de $\mathrm{N}$, mas a que recebeu a mesma solução nutritiva dos tratamentos com apenas FMA e metade da quantidade de $\mathrm{P}$ utilizada na solução completa apresentou a maior massa de matéria seca da parte aérea
(Tabela 3). A mesma testemunha apresentou igual quantidade acumulada e maior IEU do $\mathrm{N}$ e do $\mathrm{P}$ do que a testemunha que recebeu solução nutritiva completa.

O melhor desempenho dos FMAs, na ausência da bactéria diazotrófica, pode ser indicativo de um desbalanço nutricional/energético do hospedeiro, causado pela presença concomitante dos microrganismos endofíticos (FMA-bactéria diazotrófica), pois, segundo Frey-Klett et al. (2005), a micorrizosfera tem a capacidade de selecionar bactérias potencialmente benéficas para a planta, no estabelecimento da associação planta-bactéria-FMA. Isto é particularmente observado no presente trabalho, nas plantas colonizadas por Acaulospora sp. e quaisquer bactérias diazotróficas, que apesar da maior colonização radicular dos endofíticos apresentaram menor crescimento, teor, acúmulo e IEU do N, em comparação ao controle $\mathrm{T}$ - N.

Na presença de A. insolitus obteve-se maior teor de $\mathrm{P}$ na parte aérea do trigo (Tabela 6), e a colonização micorrízica também foi maior nos tratamentos em que A. insolitus foi co-inoculado com os FMAs (Tabela 2). Nos tratamentos com ambos os endófitos, o FMA Acaulospora sp. propiciou maior teor de $\mathrm{P}$, mas nas plantas colonizadas por Glomus obteve-se maior quantidade acumulada e IEU (BF1 - BF2), em razão da maior produção de matéria seca, propiciada pelo Glomus associado às bactérias (Tabela 3). Também houve maior IEU do P nas plantas colonizadas por Glomus do que

Tabela 5. Teor, quantidade acumulada e índice de eficiência de utilização do nitrogênio (IEUN) e teste F para comparação dos contrastes ortogonais obtidos entre os tratamentos. Média de cinco repetições ${ }^{(1)}$.

\begin{tabular}{|c|c|c|c|c|c|c|c|}
\hline \multirow[t]{2}{*}{ Tratamento $^{(2)}$} & \multirow{2}{*}{$\begin{array}{c}\text { Teor } \\
\left(\mathrm{g} \mathrm{kg}^{-1}\right)\end{array}$} & \multirow{2}{*}{$\begin{array}{c}\mathrm{N} \text { total } \\
\left(\mathrm{mg} \mathrm{planta}^{-1}\right)\end{array}$} & \multirow{2}{*}{$\begin{array}{l}\text { IEUN } \\
\left(\mathrm{g}^{2} \mathrm{~g}^{-1}\right)\end{array}$} & \multirow{2}{*}{$\begin{array}{l}\text { Contrastes } \\
\text { ortogonais }\end{array}$} & \multicolumn{3}{|c|}{ Teste F } \\
\hline & & & & & Teor & $\mathrm{N}$ total & IEUN \\
\hline$\overline{\mathrm{B} 1}$ & 12,75 & 38 & 236 & $\mathrm{~B}-\mathrm{BF}$ & $9,93 *$ & $2,38^{\text {ns }}$ & $11,99^{*}$ \\
\hline $\mathrm{B} 1 \mathrm{~F} 1$ & 11,98 & 37 & 265 & $\mathrm{~F}-\mathrm{BF}$ & $55,45^{*}$ & $392,39^{*}$ & $138,57^{*}$ \\
\hline $\mathrm{B} 1 \mathrm{~F} 2$ & 14,73 & 19 & 93 & BF1 - BF2 & $1,71^{\mathrm{ns}}$ & $17,11 *$ & $59,55 *$ \\
\hline B2 & 13,51 & 45 & 247 & $\mathrm{~B} 1 \mathrm{~F}-\mathrm{B} 2 \mathrm{~F}$ & $3,23^{\mathrm{ns}}$ & $0,16^{\mathrm{ns}}$ & $3,83^{\mathrm{ns}}$ \\
\hline $\mathrm{B} 2 \mathrm{~F} 1$ & 15,15 & 47 & 211 & $\mathrm{~F} 1-\mathrm{F} 2$ & $0,01^{\mathrm{ns}}$ & $1,32^{\mathrm{ns}}$ & $0,17^{\mathrm{ns}}$ \\
\hline $\mathrm{B} 2 \mathrm{~F} 2$ & 14,65 & 14 & 66 & $\mathrm{~B} 1-\mathrm{B} 2$ & $7,40^{*}$ & $2,43^{\text {ns }}$ & $4,04^{\mathrm{ns}}$ \\
\hline $\mathrm{F} 1$ & 19,62 & 134 & 362 & $\mathrm{~F}-\mathrm{T}-\mathrm{P}$ & $20,11 *$ & $0,99^{\text {ns }}$ & $0,49^{\mathrm{ns}}$ \\
\hline F2 & 19,72 & 144 & 374 & $\mathrm{~B}-\mathrm{T}-\mathrm{N}$ & $6,28^{*}$ & $4,76^{*}$ & $20,10^{*}$ \\
\hline $\mathrm{T}+\mathrm{N}$ & 25,28 & 161 & 261 & $\mathrm{BF}-\mathrm{T}-\mathrm{N}$ & $0,12^{\text {ns }}$ & $1,43^{\text {ns }}$ & $5,00 *$ \\
\hline $\mathrm{T}-\mathrm{N}$ & 14,45 & 21 & 108 & $\mathrm{~F}-\mathrm{T}+\mathrm{N}$ & $28,35^{*}$ & $10,96^{*}$ & $18,01 *$ \\
\hline \multirow[t]{4}{*}{$\mathrm{T}-\mathrm{P}$} & 19,09 & 159 & 439 & $\mathrm{~B}-\mathrm{T}+\mathrm{N}$ & $167,97^{*}$ & $273,68^{*}$ & $3,04^{\mathrm{ns}}$ \\
\hline & & & & $\mathrm{BF}-\mathrm{T}+\mathrm{N}$ & $134,58^{*}$ & $359,91^{*}$ & $19,97 *$ \\
\hline & & & & $\mathrm{B} 1-\mathrm{B} 1 \mathrm{~F} 2$ & $15,40^{*}$ & $1,90^{\mathrm{ns}}$ & $12,14 *$ \\
\hline & & & & BF $1-T-N$ & $0,01^{\mathrm{ns}}$ & $7,73 *$ & $26,96^{*}$ \\
\hline
\end{tabular}

${ }^{(1)} \mathrm{GL}=1$ e 41; $\mathrm{F}_{0}=4,08 .{ }^{(2)} \mathrm{B} 1:$ IAC12HT - Zoogloea ramigera; B2: IAC11HT - Achromobacter insolitus; F1: Glomus sp.; F2: Acaulospora sp.; $\mathrm{T}+\mathrm{N}$ : testemunha que recebeu solução nutritiva completa; T - N: testemunha que recebeu metade da quantidade de P da solução completa e não

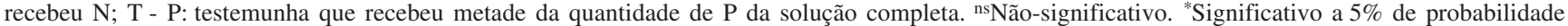
pelo teste $\mathrm{F}$. 
Tabela 6. Teor, quantidade acumulada e índice de eficiência de utilização do fósforo (IEUP) e teste F, para comparação dos contrastes ortogonais obtidos entre os tratamentos. Média de cinco repetições ${ }^{(1)}$.

\begin{tabular}{|c|c|c|c|c|c|c|c|}
\hline \multirow[t]{2}{*}{ Tratamento $^{(2)}$} & \multirow{2}{*}{$\begin{array}{c}\text { Teor } \\
\left(\mathrm{g} \mathrm{kg}^{-1}\right)\end{array}$} & \multirow{2}{*}{$\begin{array}{c}\text { P total } \\
\left(\mathrm{mg} \mathrm{planta}^{-1}\right)\end{array}$} & \multirow{2}{*}{$\begin{array}{l}\text { IEUP } \\
\left(\mathrm{g}^{2} \mathrm{~g}^{-1}\right)\end{array}$} & \multirow{2}{*}{$\begin{array}{l}\text { Contrastes } \\
\text { ortogonais }\end{array}$} & \multicolumn{3}{|c|}{ Teste F } \\
\hline & & & & & Teor & P total & IEUP \\
\hline$\overline{\mathrm{B} 1}$ & 2,36 & 7,55 & 1.357 & $\mathrm{~B}-\mathrm{BF}$ & $4,33^{*}$ & $2,90^{\mathrm{ns}}$ & $2,51^{\mathrm{ns}}$ \\
\hline B1F1 & 2,11 & 7,07 & 1.598 & $\mathrm{~F}-\mathrm{BF}$ & $44,99 *$ & $19,00 *$ & $266,25^{*}$ \\
\hline $\mathrm{B} 1 \mathrm{~F} 2$ & 3,05 & 4,90 & 532 & BF1 - BF2 & $14,48^{*}$ & $12,60 *$ & $11,46^{*}$ \\
\hline $\mathrm{B} 2$ & 2,43 & 7,80 & 1.327 & $\mathrm{~B} 1 \mathrm{~F}-\mathrm{B} 2 \mathrm{~F}$ & $4,30^{*}$ & $0,12^{\text {ns }}$ & $0,75^{\mathrm{ns}}$ \\
\hline $\mathrm{B} 2 \mathrm{~F} 1$ & 2,62 & 8,80 & 1.267 & $\mathrm{~F} 1-\mathrm{F} 2$ & $0,14^{\mathrm{ns}}$ & $0,85^{\text {ns }}$ & $14,92 *$ \\
\hline $\mathrm{B} 2 \mathrm{~F} 2$ & 3,57 & 3,90 & 323 & $\mathrm{~B} 1-\mathrm{B} 2$ & $0,03^{\mathrm{ns}}$ & $0,04^{\mathrm{ns}}$ & $0,01^{\mathrm{ns}}$ \\
\hline F1 & 1,33 & 10,60 & 5.988 & $\mathrm{~F}-\mathrm{T}-\mathrm{P}$ & $0,26^{\mathrm{ns}}$ & $8,88^{*}$ & $3,40^{\mathrm{ns}}$ \\
\hline F2 & 1,46 & 9,34 & 4.350 & $B-T-N$ & $2,00^{\mathrm{ns}}$ & $10,94 *$ & $5,87^{*}$ \\
\hline $\mathrm{T}+\mathrm{N}$ & 1,97 & 12,40 & 3.328 & $\mathrm{BF}-\mathrm{T}-\mathrm{N}$ & $0,00^{\mathrm{ns}}$ & $5,30^{*}$ & $2,04^{\mathrm{ns}}$ \\
\hline $\mathrm{T}-\mathrm{N}$ & 2,82 & 3,62 & 456 & $\mathrm{~F}-\mathrm{T}+\mathrm{N}$ & $3,57 *$ & $4,00^{\mathrm{ns}}$ & $25,15^{*}$ \\
\hline \multirow[t]{3}{*}{$\mathrm{T}-\mathrm{P}$} & 1,55 & 13,60 & 5.846 & $\mathrm{~B}-\mathrm{T}+\mathrm{N}$ & $1,91^{\mathrm{ns}}$ & $15,04^{*}$ & $29,18^{*}$ \\
\hline & & & & $\mathrm{BF}-\mathrm{T}+\mathrm{N}$ & $9,76^{*}$ & $31,00^{*}$ & $51,06^{*}$ \\
\hline & & & & $\mathrm{B} 2-\mathrm{B} 2 \mathrm{~F} 2$ & $10,72 *$ & $7,60 *$ & $5,60 *$ \\
\hline
\end{tabular}

${ }^{(1)} \mathrm{GL}=1$ e 41; $\mathrm{F}_{0}=4,08 .{ }^{(2)} \mathrm{B} 1:$ IAC12HT - Zoogloea ramigera; B2: IAC11HT - Achromobacter insolitus; F1: Glomus sp.; F2: Acaulospora sp.; $\mathrm{T}+\mathrm{N}$ : testemunha que recebeu solução nutritiva completa; $\mathrm{T}$ - N: testemunha que recebeu metade da quantidade de $\mathrm{P}$ da solução completa e não

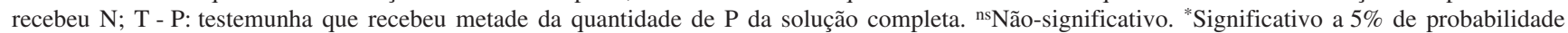
pelo teste F.

nas colonizadas por Acaulospora (F1 - F2). Nos tratamentos em que somente bactérias diazotróficas foram inoculadas (BF - B), as plantas apresentaram menor teor de $\mathrm{P}$ do que com a co-inoculação dos FMAs, o que demonstra efeito sinérgico da co-inoculação, principalmente de Acaulospora sp., como observado para o teor de $\mathrm{N}$, em que A. insolitus (B2 - B2F2) foi co-inoculado. Entretanto, não houve diferenças na quantidade acumulada e no IEU do $\mathrm{P}$ nesses tratamentos (BF - B). Também houve menor teor de $\mathrm{P}$ nos tratamentos que continham somente FMAs (BF - F).

Ao se compararem os tratamentos que continham somente bactérias diazotróficas ou bactérias com FMAs, em relação à testemunha que recebeu a mesma solução nutritiva ( $\mathrm{T}$ - N), observou-se que, nos tratamentos com bactérias diazotróficas somente $(\mathrm{B}-\mathrm{T}-\mathrm{N})$, obteve-se igual teor de $\mathrm{P}$, mas o dobro da quantidade acumulada e o triplo do índice de eficiência de utilização. Entretanto, quando as bactérias estavam em conjunto com os FMAs (BF - T - N), o teor e o IEU não foram alterados, porém obteve-se maior quantidade acumulada de P (Tabela 6).

As plantas na presença apenas dos FMAs não diferiram da testemunha $(\mathrm{F}-\mathrm{T}-\mathrm{P})$, no teor e IEU do $\mathrm{P}$, mas apresentaram significativamente menor quantidade acumulada de $\mathrm{P}$ e menor massa de matéria seca da parte aérea do que a testemunha (Tabela 3), o que indica um efeito parasítico. Porém, as plantas da testemunha que receberam solução nutritiva completa $(\mathrm{T}+\mathrm{N})$ apresentaram maior teor de $\mathrm{P}$, mas não diferiram na quantidade acumulada e apresentaram menor IEU de $\mathrm{P}$ do que as plantas dos tratamentos com FMAs isoladamente $(\mathrm{F}-\mathrm{T}+\mathrm{N})$.

\section{Conclusões}

1. Há efeito sinérgico da co-inoculação do fungo micorrízico do gênero Acaulospora e dos isolados IAC11HT (Achromobacter insolitus) e IAC12HT (Zoogloea ramigera) na colonização das raízes do trigo por bactérias diazotróficas.

2. O fungo micorrízico do gênero Glomus é mais eficiente em aumentar o crescimento, acúmulo e aproveitamento do nitrogênio e do fósforo pelas plantas do que Acaulospora sp. co-inoculado com bactérias diazotróficas.

3. A inoculação isolada de Achromobacter e Zoogloea duplica o crescimento, acúmulo e aproveitamento do nitrogênio e fósforo pelas plantas.

\section{Agradecimentos}

À Fapesp, pelo auxílio financeiro e concessão de bolsa.

\section{Referências}

ARTURSSON, V.; FINLAY, R.D.; JANSSON, J.K. Interactions between arbuscular mycorrhizal fungi and bacteria and their potential for stimulating plant growth. Environmental Microbiology, v.8, p.1-10, 2006. 
AZCÓN, R.; OCAMP, J.A. Factors affecting the vesicular-arbuscular infection and mycorrhizal dependency of thirteen wheat cultivars. New Phytologist, v.87, p.677-685, 1981.

BAREA, J.M.; POZO, M.J.; AZCÓN, R.; AZCÓN-AGUILAR, C. Microbial co-operation in the rhizosphere. Journal of Experimental Botany, v.56, p.1761-1778, 2005.

BEHL, R.K.; SHARMA, H.; KUMAR, V.; NARULA, N. Interactions amongst mycorrhiza, Azotobacter chroococcum and root characteristics of wheat varieties. Journal of Agronomy \& Crop Science, v.189, p.151-155, 2003.

BHOWMIK, S.N.; SINGH, C.S. Mass multiplication of AM inoculum; effect of plant growth-promoting rhizobacteria and yeast in rapid culturing of Glomus mosseae. Current Science, v.86, p.705709, 2004.

BIANCIOTTO, V.; GENRE, A.; JARGEAT, P.; LUMINI, E.; BECARD, G.; BONFANTE, P. Vertical transmission of endobacteria in the arbuscular mycorrhizal fungus Gigaspora margarita through generation of vegetative spores. Applied Environmental Microbiology, v.70, p.3600-3608, 2004.

BIRÓ, B.; KOVES-PECHY, K.; VORS, I.; TAKACS, T.; EGGENBERG, P.; STRASSER, R.J. Interrelations between Azospirillum and Rhizobium nitrogen-fixers and arbuscular mycorrhizal fungi in the rhizosphere of alfalfa in sterile, AMF-free or normal soil conditions. Applied Soil Ecology, v.15, p.159-168, 2000.

BODDEY, R.M.; BALDANI., V.L.D.; BALDANI, J.I.; DÖBEREINER, J. Effect of inoculation of Azospirillum spp. on nitrogen accumulation by field-grown wheat. Plant and Soil, v.95, p.109-121, 1986.

CLARK, R.B.; ZETO, S.K.;ZOBEL. Arbuscular mycorrhizal fungal isolate effectiveness on growth and root colonization of Panicum virgatum in acidic soil. Soil Biology and Biochemistry, v.31, p.1757-1763, 1999.

DOBBELAERE, S.; CROONENBORGHS, A.; THYS, A.; BROEK, A.V.; VANDERLEYDEN, J. Phytostimulatory effect of Azospirillum brasilense wild type and mutant strains altered in IAA production on wheat. Plant and Soil, v.212, p.155-164, 1999.

DÖBEREINER, J.; BALDANI, J.I.; BALDANI, V.L.D. Como isolar e identificar bactérias diazotróficas de plantas não leguminosas. Brasília: Embrapa-SPI, 1995. 60p.

FREY-KLETT, P.; CHAVATTE, M.; CLAUSSE, M.; COURRIER, S.; LE ROUX, C.; RAAIJMAKERS, J.; MARTINOTTI, M.G.; PIERRAT, J.; GARBAYE, J. Ectomycorrhizal symbiosis affects functional diversity of rhizosphere fluorescent pseudomonads. New Phytologist, v.165, p.317-328, 2005.

FURLANI, P.R.; FURLANI, A.M.C. Composição e pH das soluções nutritivas para estudos fisiológicos e seleção de plantas em condições nutricionais adversas. Campinas: IAC, 1988. 34p. (IAC. Boletim Técnico, 78).

GRAHAM, J.H.; ABBOTT, L.K. Wheat responses to aggressive and non aggressive arbuscular mycorrhizal fungi. Plant and Soil, v.220, p.207-218, 2000.
HOAGLAND, D.R.; ARNON, D.I. The water-culture method for growing plants without soil. Irvine: University of California, 1950. $347 \mathrm{p}$.

INIGUEZ, A.L.; DONG, Y.; TRIPLETT, E.W. Nitrogen fixation in wheat provided by Klebsiella pneumoniae 342. Molecular PlantMicrobe Interations, v.17, p.1078-1085, 2004.

ISOPI, R.; FABRI, P.; DELGALLO, M.; PUPPI, G. Dual inoculation of Sorghum bicolor (L.) Moench subsp. bicolor with vesicular arbuscular mycorrhizas and Acetobacter diazotrophicus. Symbiosis, v.18, p.43-55, 1995.

LI, C.Y.; STRZELCZYK, E. Belowground microbial process underpin forest productivity. Phyton, v.40, p.129-134, 2000.

PAULA, M.A.; REIS, V.M.; DÖBEREINER, J. Interations of Glomus clarum with A. dizotrophicus in infection of sweet potato, sugar cane, sweet sorghum. Biology and Fertility of Soils, v.11, p.111-115, 1991.

PAULA, M.A.; URQUAIA, S.; SIQUEIRA, J.O.; DÖBEREINER, J. Synergistic effects of vesicular-arbuscular mycorrhizal fungi and diazotrophic bacteria on nutrition and growth of sweet potato (Ipomoea batatas). Biology and Fertility of Soils, v.14, p.61-66, 1992.

PHILLIPS, P.S.; HAYMAN, D.S. Improved procedures for clearing roots and staining parasitic and vesicular arbuscular mycorrhizal fungi for rapid assessment of infection. Transactions of the British Mycological Society, v.55, p.158-161, 1970.

ROESCH, L.F.; CAMARGO, F.O.; SELBACH, P.A.; SÁ, E.S. Reinoculação de bactérias diazotróficas aumentando o crescimento de plantas de trigo. Ciência Rural, v.35, p.1201-1204, 2005.

SALA, V.M.R.; FREITAS, S.S.; DONZELI, V.P.; FREITAS, J.G.; GALLO. P.B.; SILVEIRA, A.P.D. Ocorrência e efeito de bactérias diazotróficas em genótipos de trigo. Revista Brasileira de Ciência do Solo, v.29, p.345-352, 2005.

SIDDQI, M.Y.; GLASS, A.D.M. Utilization index: a modified approach to the estimation and comparison of nutrient utilization efficiency in plants. Journal of Plant Nutrition, v.4, p.289-312, 1981.

TSAVKELOVA, E.A.; KLIMOVA, S.Y.; CHERDYNTSEVA, T.A.; NETRUSOV, A.I. Microbial producers of plant growth stimulators and their practical use: a review. Applied Biochemistry and Microbiology, v.42, p.117-126, 2006.

VÁZQUEZ, M.M.; CÉSAR, S.; AZCÓN R.; BAREA, J.M. Interactions between arbuscular mycorrhizal fungi and other microbial inoculants (Azospirillum, Pseudomonas, Trichoderma) and their effects on microbial population and enzyme activities in the rhizosphere of maize plants. Applied Soil Ecology, v.15, p.261$272,2000$.

ZAIED, K.A.; EL-HADY, A.H.; AFIFY, A.H.; NASSEF, M.A. Yield and nitrogen assimilation of winter wheat inoculated with new recombinant inoculants of rhizobacteria. Pakistan Journal of Biological Sciences, v.4, p.344-358, 2003. 